\title{
Smart Product-Service Systems: A Novel Transdisciplinary Sociotechnical Paradigm
}

\author{
Pai ZHENG ${ }^{\mathrm{a}, \mathrm{b}, 1}$, Zuoxu WANG ${ }^{\mathrm{a}}$ and Chun-Hsien $\mathrm{CHEN}^{\mathrm{a}}$ \\ ${ }^{a}$ School of Mechanical and Aerospace Engineering, Nanyang Technological \\ University, Singapore, 639798 \\ ${ }^{\mathrm{b}}$ Delta-NTU Corporate Laboratory, School of Electrical and Electronic Engineering, \\ Nanyang Technological University, Singapore, 639798
}

\begin{abstract}
The third-wave of IT competition have embraced a promising market of low cost, high performance smart, connected products (SCP). Owing to their unique capabilities, SCPs together with their generated smart services, as a solution bundle can fulfil the everchanging individual user's needs. Meanwhile, manufacturers/service providers leverage massive user generated data and product sensed data via the Internet-of-Things (IoT) for evergreen design innovation. This emerging IT-driven transdisciplinary engineering paradigm is named Smart Product-Service Systems (Smart PSS), which is an ecosystem consisting of various stakeholders as the key players for open innovation (social aspect), intelligent systems as the infrastructure to enable smartness and connectedness (technical aspect), and digital servitization as the value proposition to make higher profits (business aspect). Though similar terminologies have been utilized to describe such paradigm, none of them emphasizes its transdisciplinary essence, as a sociotechnical system. Moreover, scarcely any work addresses its lifecycle perspectives for sustainability concerns. Aiming to fill these gaps, this research provides a fundamental basis of Smart PSS by summarizing typical works from technical, social, and business aspects, respectively. Furthermore, its lifecycle perspectives in a circular economy is depited to motivate more in-depth research in the near future.
\end{abstract}

Keywords. Product-service Systems, Smart Product, Value Co-creation, Circular Economy, Sociotechnical System

\section{Introduction}

The prevailing digital technologies, including Internet-of-Things (IoT), cloud/edge computing, and Big Data analytics has enabled the industrial digital transformation towards digital servitization (technical aspect) [1]. This IT-driven servitized business strategy is named smart product-service systems (Smart PSS) [2][3], where smart, connected products (SCPs) and their generated advanced services are delivered by the service provider/manufacturer as a single solution bundle to achieve individual customer satisfaction with sustainable concerns (business aspect). Meanwhile, different stakeholders are enabled by those disruptive digital technologies/tools, to actively

\footnotetext{
${ }^{1}$ Corresponding Author, Email: ericzheng@ntu.edu.sg.
} 
engaged in the value creation process by contributing their own data or knowledge for open innovation (social aspect).

Nevertheless, as an emerging discipline, though similar terminologies have been utilized to describe such paradigm, none of them emphasizes its transdisciplinary essence, as a sociotechnical system. Moreover, scarcely any work addresses its lifecycle perspectives for sustainability concerns. Aiming to fill these gaps, this research provides a fundamental basis of Smart PSS by summarizing typical works from technical, social, and business aspects, respectively. Furthermore, its lifecycle perspectives in a circular economy is depited to motivate more in-depth research in the near future. The rest of this paper is organized as follows: Section 1 provides the basic notions of Smart PSS including its typical definitions and key elements. Section 2 depicts the Smart PSS as a sociotechnical system, including technical aspect, as a data-driven IoT-enabled platform-based solution package with smartness and connectedness; social aspect as an open innovation eco-system; and business aspect as a service-dominant logic based strategy. The lifecycle considerations of Smart PSS in a circular economy is further briefly discussed in Section 3. Major findings of this work are concluded in Section 4 to motivate more in-depth works in the future.

\section{Basic notions of Smart PSS}

The concept of digital transformation can be traced back to 2009, where IoT was introduced and prevailingly embraced by industrial companies, and there has been a wide discussion of digitization-enabled services, i.e. servitization. Nevertheless, till 2014, Valencia et al. [2][4] coined the terminology, Smart PSS, to describe such digital servitization as "smart products and its generated e-services into a single solution by embracing disruptive ICT." Ever since then, serveral definitions have been introduced by extending its scope with product digitalization and various stakeholders engagement considerations [3-8], as shown in Table 1.

Though lacking a unified defintion, Smart PSS shares some common senses, including value co-creation, digital servitization, and product-service ecosystem with sustainability concerns. Meanwhile, Smart PSS is composed by various stakeholders, smart, connected products (SCPs) and its generated smart services, and smart environment (intelligent context) to meet individual customer needs.

Table 1. Smart PSS definitions and key elements.

\begin{tabular}{|c|c|c|}
\hline Reference & Definitions & Key elements \\
\hline $\begin{array}{l}\text { Valencia et } \\
\text { al. [2][4] }\end{array}$ & $\begin{array}{l}\text { "smart products and its generated e-services } \\
\text { into a single solution by embracing disruptive } \\
\text { ICT." }\end{array}$ & $\begin{array}{l}\text { Stakeholder involvement, complex } \\
\text { market offerings, ICT technologies, } \\
\text { e-services, interactions between the } \\
\text { smart PSS and end-users, context, } \\
\text { and a life-long development issue }\end{array}$ \\
\hline $\begin{array}{l}\text { Kuhlenkötter } \\
\text { et al. [5] }\end{array}$ & $\begin{array}{l}\text { "A digital-based ecosystem of value creation } \\
\text { characterized by high complexity, dynamics } \\
\text { and interconnectedness among stakeholders." }\end{array}$ & l \\
\hline $\begin{array}{l}\text { Zheng et al. } \\
{[3][6][7]}\end{array}$ & $\begin{array}{l}\text { "An IT-driven value co-creation business } \\
\text { strategy consisting of various stakeholders as } \\
\text { the players, intelligent systems as the } \\
\text { infrastructure, smart, connected products as } \\
\text { the media and tools, and their generated }\end{array}$ & $\begin{array}{l}\text { SCPs and its generated smart } \\
\text { services, smart environment } \\
\text { (intelligent systems) and various } \\
\text { stakeholders }\end{array}$ \\
\hline
\end{tabular}




\begin{tabular}{ll}
\hline & $\begin{array}{l}\text { services as the key values delivered that } \\
\text { continuously strives to meet individual } \\
\text { customer needs in a sustainable manner." }\end{array}$ \\
\hline Liu. et al. [8], & $\begin{array}{l}\text { "A platform service ecosystem, in which } \\
\text { platform is made up of smart products and } \\
\text { smart services, while multiple service systems } \\
\text { constitute a service ecosystem." }\end{array}$ \\
\hline
\end{tabular}

\section{Smart PSS as a sociotechnical system}

This section depicts Smart PSS from sociotechnical system perspective, including technical aspect, social aspect and business aspect, respectively.

\subsection{Technical aspect-smartness and connectedness}

As mentioned earlier, Smart PSS derives from the state-of-the-art IT (digital technologies), of which IoT provides the ubiquitous connectivity environment for reliable data collection and information communication, cloud computing offers the service-oriented IT architecture with pervasive computation efficiency (information processing), and Big Data analytic techniques leverages the realization of knowledge management with intelligent decision makings (business intelligence). Hence, the development of Smart PSS can be seen as a data-driven (informatics-based), platformbased solution design process, where two typical types, i.e. product-dependent Smart PSS, and product-independent Smart PSS can be further categorized (see Table 2).

Product-dependent Smart PSS stands for the ones which final solution bundle is highly related to the physical products themselves, including product configuration/reconfiguraiton systems, embedded open toolkits, and cyber-physical systems (CPS) or digital twin. For exmaple, real time monitoring/control of the machine tools in the smart manufacturing shop floor.

Product-independent Smart PSS stands for the ones which final solution bundle is independent with the composition of physical products. It follows the service-dominant logic by utilizing the modular service platform to generate various e-services. For instance, smart cooking guidance downloaded from the mobile apps.

Table 2. Two-types of data-driven platform-based Smart PSS.

\begin{tabular}{|c|c|c|c|}
\hline Categories & Definition & Types & References \\
\hline \multirow{3}{*}{$\begin{array}{l}\text { Product- } \\
\text { dependent }\end{array}$} & \multirow{3}{*}{$\begin{array}{l}\text { A solution bundle consisting of various } \\
\text { digitized physical products and its } \\
\text { dependent smart e-services. }\end{array}$} & Product re-/configuration system & {$[5][3][10]$} \\
\hline & & Embedded open toolkits & {$[11]$} \\
\hline & & CPS/Digital Twin & {$[12][13]$} \\
\hline $\begin{array}{l}\text { Product- } \\
\text { independent }\end{array}$ & $\begin{array}{l}\text { A solution bundle consisting of various } \\
\text { smart e-services, which are independent } \\
\text { with the composition of physical products. }\end{array}$ & Service platform & {$[7][8][9]$} \\
\hline
\end{tabular}

\subsection{Social aspect - open innovation 2.0}

Owing to the unique characteristics of Smart PSS, it matches well with the prevailing paradigm of Open innovation 2.0 [14], which utilises disruptive technologies, e.g. IoT, 
CPS and cloud computing, to solve societal challenges profitably and sustainably. It is a vision of shared value, sustainable prosperity and improvements in human well-beings. For example, the smart city services (e.g. traffic planning, air pollution monitoring) from large-scale smart mobile devices offered by a large number of users to other users/service providers (crowd sensing). Meanwhile, from industrial perspective, Smart PSS can be seen as an ecosystem-centric view of open innovation. In this co-creation business model, users actively interact with manufacturers enabled by the advanced IT and become an integral part of the innovation process. Their experience, i.e. user experience, and knowledge drives the innovation, while the value is generated by the shared profit among users, services and service providers/manufacturers. Table 3 depicts the typcial works of Smart PSS with open innovation considerations, by looking at its players (actors), cocreation stages and mechanisms. Meanwhile, another major concern is the user's privacy when service provider collecting usage data. To the authors' knowledge, solution design should follow the legal constraints, e.g. GDPR (general data privacy regulation), where no personal data is collected and ensure users' awareness and consent to the data collected as well.

Inspired by works of Liu et al. [8, 9], we assume co-creation contains three typical stages along the Smart PSS development process, i.e. co-design of the value proposition, co-implementation in the interactive value, and co-evaluation of the performance assessment. Meanwhile, derived from [15], there are two types of co-creation mechanisms, i.e. perceptive mechanism allowing the companies to identify, assess, and address specific customer needs; and responsive mechanism entailing companies' quick and proactive react to their customers' changing and emerging demands to participate in the value co-creation. Both the co-creation process and its mechanisms enable companies to fulfil dynamic changes of customer needs in an open innovation manner.

Table 3. Open innovation perspectives of Smart PSS.

\begin{tabular}{lllll}
\hline ID & Author, Year & Actors & Co-creation stages & Mechanisms \\
\hline 1 & Valencia et al. [2] [4] & $\begin{array}{l}\text { Service provider and } \\
\text { consumers }\end{array}$ & $\begin{array}{l}\text { Co-design and } \\
\text { evaluation }\end{array}$ & $\begin{array}{l}\text { Perceptive, } \\
\text { Responsive }\end{array}$ \\
\hline 2 & Takenaka et al. [16] & $\begin{array}{l}\text { Service provider and } \\
\text { consumers }\end{array}$ & Co-evaluation & Responsive \\
\hline 3 & Marilungo et al. [17] & $\begin{array}{l}\text { Platform provider and end } \\
\text { users }\end{array}$ & Co-implementation & $\begin{array}{l}\text { Perceptive, } \\
\text { Responsive }\end{array}$ \\
\hline 4 & Liu et al. [8], [9] & $\begin{array}{l}\text { Manufacturer, service } \\
\text { provider and customer }\end{array}$ & $\begin{array}{l}\text { Co-design, evaluation, } \\
\text { and implementation }\end{array}$ & $\begin{array}{l}\text { Perceptive, } \\
\text { Responsive }\end{array}$ \\
\hline & Zheng P, et al. [3] [7] & $\begin{array}{l}\text { Manufacturer/designer, } \\
\text { service provider, and users }\end{array}$ & $\begin{array}{l}\text { Co-design, evaluation, } \\
\text { and implementation }\end{array}$ & $\begin{array}{l}\text { Perceptive, } \\
\text { Responsive }\end{array}$ \\
\hline
\end{tabular}

\subsection{Business aspect-digital servitization}

Smart PSS, as an IT-driven value co-creation business strategy, leverages the platformbased strategies and follows the three typical PSS business models [18], as folows:

- Product-oriented services, which emphasizes the sales of products, but some extra advanced services are added. 
- Use-oriented services, which the product stays in ownership with the provider, and is made available in a different form, and sometimes shared by a number of users.

- Result-oriented services, where client and provider in principle agree on a result, and there is no pre-determined product involved.

Following this manner, the typical works and its business model are depicted in Table 3. It can be found that the application scenarios has a wide scope covering smart living, smart city and smart manufacturing fields. Meanwhile, although the business models fit in the previous defined three categories, nevertheless, both products and services are becoming ever connected and smart. Hence, it enables the companies to flexibly combine two or three types of servitization business models into an overall concern. For example, BMW sells its cars with maintenance servies in a product-oriented way, but also can provide shared BMW rental services in a use-oriented manner.

Table 4. Typical types of business models of Smart PSS.

\begin{tabular}{llll}
\hline Business models & Type & Applications & Industrial Sector \\
\hline \multirow{2}{*}{ Product-oriented } & $\begin{array}{l}\text { Product-related services or } \\
\text { advisory }\end{array}$ & $\begin{array}{l}\text { Smart wearable mask[3]; } \\
\text { Smart appliances [16]; } \\
\text { Machine maintenance [19] }\end{array}$ & \\
\cline { 1 - 2 } Use-oriented & $\begin{array}{l}\text { Product lease, renting or } \\
\text { sharing, or pooling }\end{array}$ & $\begin{array}{l}\text { Car2Go [20], cloud-based } \\
\text { design/manufacturing [21] }\end{array}$ & $\begin{array}{l}\text { Smart living; } \\
\text { Smart city; }\end{array}$ \\
\cline { 1 - 2 } Result-oriented & $\begin{array}{l}\text { Activity management } \\
\text { /outsourcing, pay-per-service } \\
\text { unit, or functional result }\end{array}$ & $\begin{array}{l}\text { Rolls- Royce aircraft } \\
\text { engine [22]; }\end{array}$ & \\
\hline
\end{tabular}

From the summary of existing works, one can find that Smart PSS, as a complex system, many aspects should be considered to enable its development success and satisfy individual customer needs. Moreover, as the sociotechnical system, the sustainable issues of Smart PSS should also be addressed in a circular economy.

\section{Smart PSS lifecycle in the circular economy}

Based on the above information, Figure 1 depicts the overview of Smart PSS from a product-dependent lifecycle perspective in the circular economy. Generally, an engineering product lifecycle can be classified into five sequential stages i.e. design stage, manufacturing stage, distribution stage, usage stage and end-of-life stage. The horizontal arrow (in blue) presents the different implementation stages of Smart PSS along the engineering product lifecyle. Each orange block stands for a user involved stage, where different stakeholders engage into a co-creation manner. Meanwhile, the vertical arrow (in blue) represents the digital-servitization process enabled by the digital technologies (i.e. digital twin). By exploiting the techniques of cloud, IoT and CPS, a digital-twin of SCOAP development (i.e. two-way arrow) along its lifecycle can be established inbetween the specific physical and cyber models of each stage in a cost-efficient manner. User/manufacturer/product-generated massive data is recorded and analysed in the cloud-based smart service environment, to enable real-time communication (e.g. monitoring, control, optimization, and autonomous) between the physical and virtual space.

Table 5 gives a comprehensive review of existing Smart PSS studies and its application scenarios. One can find that though different types of Smart PSS has been 
adopted/adapted along the lifecycle, few cares about the circular economy issue. As indicated by Alcayaga et al. [23], there is still a lack of sufficient studies in the smartcircular system to contribute to the sustainability issues with extended product-service lifespan, increased resource efficiency and closed-the-loop considerations. Nevertheless, it is suggested that the closed-loop process can also be enabled by the digital technologies for smart remanufacturing (e.g. material damage assessment by smart image processing), and recycling (e.g. smart warning of battery life-end) for value re-generation.

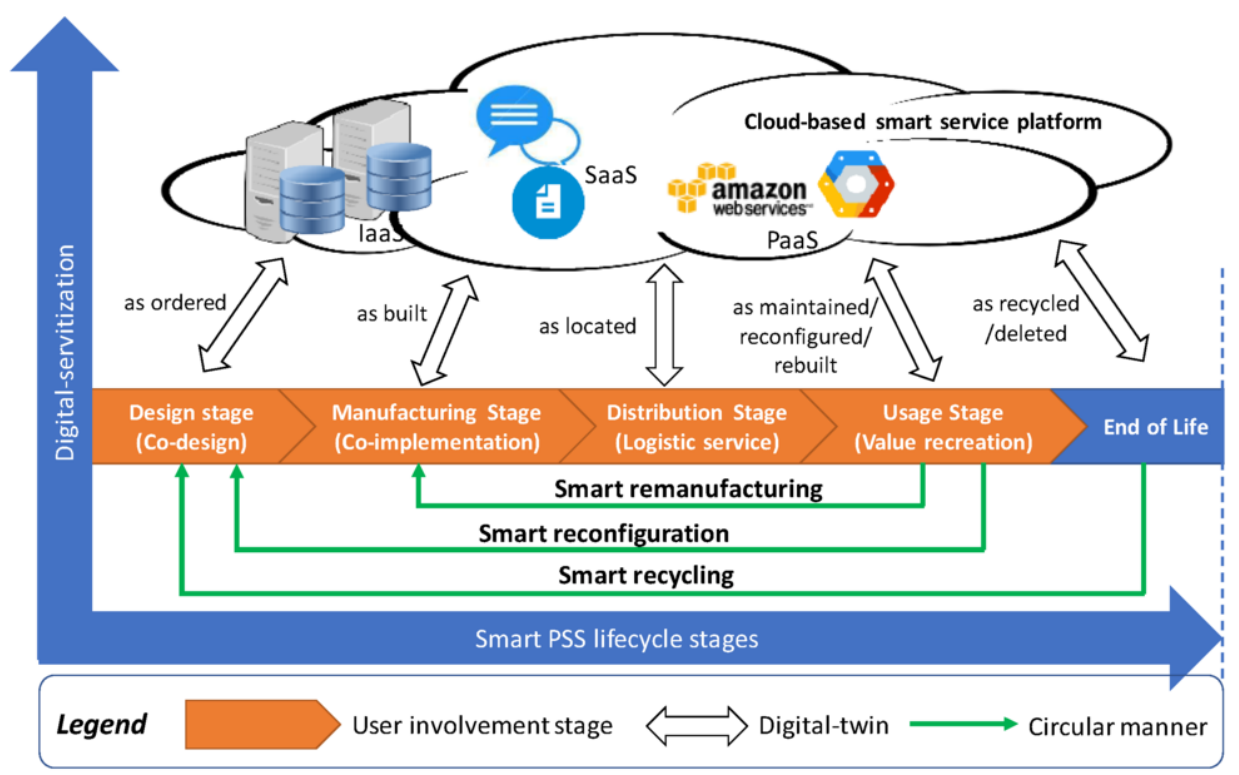

Figure 1. Smart PSS lifecycle in a circular economy (derived from [24]).

Table 5. Smart PSS lifecycle development categories and specifications.

\begin{tabular}{llll}
\hline Stage & Category & Specification & Reference \\
\hline Design stage & Requirement management & Requirement capture \& evaluation & {$[9][25]$} \\
\cline { 2 - 4 } & Smart design & Product development & {$[3][24]$} \\
\cline { 2 - 4 } & & Service development/innovation & {$[3][26]$} \\
\hline Manufacturing stage & Smart production & Production plan & {$[27][12]$} \\
\cline { 2 - 4 } & & Production reconfiguration & {$[28]$} \\
\hline \multirow{2}{*}{$\begin{array}{l}\text { Distribution/logistics } \\
\text { stage }\end{array}$} & Smart inspection & Geometry assurance & {$[29]$} \\
\hline Usage stage & Smart reconfiguration & Engineering change management & {$[6]$} \\
\cline { 2 - 4 } & & Reconfiguration of smart product & {$[10]$} \\
\cline { 2 - 4 } & Smart remanufacturing & Product remanufacturing & {$[23]$} \\
\cline { 2 - 4 } & $\begin{array}{l}\text { Smart } \\
\text { operation/maintenance }\end{array}$ & Performance assessment & {$[19]$} \\
\cline { 2 - 4 } & Smart recycling & Monitor, maintenance, diagnosis & {$[30]$} \\
\hline End-of-life stage & Product recycling & {$[23]$} \\
\hline
\end{tabular}




\section{Conclusion}

Smart PSS, as an emerging IT-driven business strategy, depicts the digital transformation of industrial companies towards digital servitizatioin, by embracing the advanced technologies to offer personalized product-service as a solution bundle with higher profits. In essence, this transdiciplinary paradigm requires one to take technical aspect, social aspect, and business aspect into an overall consideration. Motivated by this, and based on the existing studies, this research provides the fundamental basis of Smart PSS by summarizing typical works from those three aspects, respectively.

Technical aspect. Smart PSS is developed in a data-driven platform-based manner, enabled by the advanced digital technologies. IoT is essential to enables the ubiquitous connectivity, cloud/cloud-edge computing assures the information processing efficiency, and Big Data analytics supports the realization of real smartness.

Social aspect. Smart PSS operates in a shared economy manner, matching well with the concept of Open Innovation 2.0 where human and social well-being are the utlimate goal with sustainability concerns.

Business aspect. Smart PSS depicts the digital servitization business model, where service platform is fundamental to connect different parties for value co-creation process.

Furthermore, Smart PSS lifecycle perspectives in a circular economy is also discussed, where it is suggested that further studies should consider value re-generation process, including reconfiguration, remanufacturing, and recycling in a close-loop manner. It is hoped this paper, as a macro-level study, can set the basis to attract more open discussions and in-depth research from both academia and industries in the future.

\section{Acknowledgement}

This work was conducted within the Delta-NTU Corporate Lab for Cyber-Physical Systems with funding support from Delta Electronics Inc and the National Research Foundation (NRF) Singapore under the Corporate Laboratory @ University Scheme (Ref. RCA-16/434; SCO-RP1) at Nanyang Technological University, Singapore.

\section{References}

[1] C. Lerch and M. Gotsch, Digitalized Product-Service Systems in Manufacturing Firms: A Case Study Analysis, Res. Manag., Vol. 58, No. 5, pp. 45-52, 2015.

[2] A. Valencia, R. Mugge, J. P. L. Schoormans, and H. N. J. Schifferstein, Challenges in the design of smart product-service systems (PSSs): Experiences from practitioners, 19th DMI Acad. Des. Manag. Conf., no. September, pp. 1-21, 2014.

[3] P. Zheng, T.-J. Lin, C.-H. Chen, and X. Xu, A systematic design approach for service innovation of smart product-service systems, J. Clean. Prod., Vol. 201, pp. 657-667, 2018.

[4] A. Valencia, R. Mugge, J. P. L. Schoormans, and H. N. J. Schifferstein, The Design of Smart ProductService Systems (PSSs): An Exploration of Design Characteristics, Int. J. Des., Vol. 9, No. 1, pp. $13-28,2015$.

[5] B. Kuhlenkötter et al., New Perspectives for Generating Smart PSS Solutions - Life Cycle, Methodologies and Transformation, Procedia CIRP, Vol. 64, pp. 217-222, 2017.

[6] P. Zheng, C. Chen, and S. Shang, Towards an automatic engineering change management in smart product- service systems - A DSM-based learning approach, Advanced Engineering Informatics, Vol. 39, no. January, pp. 203-213, 2019.

[7] P. Zheng, Z. Wang, and C. Chen, Industrial smart product-service systems solution design via hybrid concerns, Procedia CIRP, Vol. 83, pp. 187-192, 2019. 
[8] Z. Liu, X. Ming, W. Song, S. Qiu, and Y. Qu, A perspective on value co-creation-oriented framework for smart product-service system, Procedia CIRP, Vol. 73, pp. 155-160, 2018.

[9] Z. Liu and X. Ming, A framework with revised rough-DEMATEL to capture and evaluate requirements for smart industrial product-service system of systems, Int. J. Prod. Res., pp. 1-19, 2019.

[10] M. Abramovici, J. C. Göbel, and P. Savarino, Reconfiguration of smart products during their use phase based on virtual product twins, CIRP Ann. - Manuf. Technol., vol. 66, no. 1, pp. 165-168, 2017.

[11] P. Zheng, X. Xu, and C.-H. Chen, A data-driven cyber-physical approach for personalised smart, connected product co-development in a cloud-based environment, J. Intell. Manuf., pp. 1-16, 2018.

[12] T. H. J. Uhlemann, C. Lehmann, and R. Steinhilper, The Digital Twin: Realizing the Cyber-Physical Production System for Industry 4.0, Procedia CIRP, Vol. 61, pp. 335-340, 2017.

[13] R. Söderberg, K. Wärmefjord, J. S. Carlson, and L. Lindkvist, Toward a Digital Twin for real-time geometry assurance in individualized production, CIRP Ann. - Manuf. Technol., Vol. 66, No. 1, pp. 137-140, 2017.

[14] M. Curley, Twelve principles for open innovation 2.0, Nature, vol. 533, pp. 314-316, 2016.

[15] S. Lenka, V. Parida, J. Wincent, Digitalization Capabilitiesas Enablers of Value Co-Creation in Servitizing Firms, Psychology \& Marketing. Vol. 34, no. January, pp. 92-100, 2017.

[16] G. A. Vazquez-Martinez, J. L. Gonzalez-Compean, V. J. Sosa-Sosa, M. Morales-Sandoval, and J. C. Perez, CloudChain: A novel distribution model for digital products based on supply chain principles, Int. J. Inf. Manage., Vol. 39, no. December 2017, pp. 90-103, 2018.

[17] T. Takenaka, Y. Yamamoto, K. Fukuda, A. Kimura, and K. Ueda, Enhancing products and services using smart appliance networks, CIRP Ann. - Manuf. Technol., Vol. 65, no. 1, pp. 397-400, 2016.

[18] A. Tukker, Eight types of product-service system: eight ways to sustainability? Experiences from suspronet. Vol. 260, pp. 246-260, 2004.

[19] E. Marilungo, A. Papetti, M. Germani, and M. Peruzzini, From PSS to CPS Design: A Real Industrial Use Case Toward Industry 4.0, Procedia CIRP, Vol. 64, pp. 357-362, 2017.

[20] J. Lee, H. D. Ardakani, S. Yang, and B. Bagheri, Industrial Big Data Analytics and Cyber-physical Systems for Future Maintenance \& Service Innovation, Procedia CIRP, vol. 38, pp. 3-7, 2015.

[21] Car2Go: https://www.car2go.com/US/en/ (Accessed on 28/03/2019)

[22] X. Jin, S. Yu, P. Zheng, Q. Liu, and X. Xu, Cloud-based approach for smart product personalization, Procedia CIRP, Vol. 72, pp. 922-927, 2018.

[23] Rolls-Royce Carestore: https://www.rolls-royce.com/products-and-services/civilaerospace/aftermarket-services.aspx (Accessed on 28/03/2019)

[24] P. Zheng, Y. Lin, C.-H. Chen, and X. Xu, Smart, connected open architecture product: an IT-driven co-creation paradigm with lifecycle personalization concerns, Int. J. Prod. Res., Vol. 57, No. 8, pp. 2571-2584, 2019.

[25] Z. Wang, P. Zheng, and C. Chen, A graph-based requirement elicitation approach in the context of product-service systems, 48th International Conference on Computers and Industrial Engineering, Auckland, New Zealand, 2018.

[26] A. Corradi et al., Smart Appliances and RAMI 4.0: Management and Servitization of Ice Cream Machines, IEEE Trans. Ind. Informatics, Vol. 15, No. 2, pp. 1007-1016, 2018.

[27] M. F. Filho, Y. Liao, E. R. Loures, and O. Canciglieri, Self-Aware Smart Products: Systematic Literature Review, Conceptual Design and Prototype Implementation, Procedia Manufacturing, Vol. 11, no. June, pp. 1471-1480, 2017.

[28] S. Brad and M. Murar, Employing smart units and servitization towards reconfigurability of manufacturing processes, Procedia CIRP, Vol. 30, pp. 498-503, 2015.

[29] A. Alcayaga, E. G. Hansen, and M. Wiener, Towards a Framework of Smart-Circular Systems: An Integrative Literature Review, J. Clean. Prod., Vol. 221, pp. 622-634, 2019.

[30] E. Maleki et al., Ontology-Based Framework Enabling Smart Product-Service Systems: Application of Sensing Systems for Machine Health Monitoring, IEEE Internet Things J., Vol. 5, No. 6, pp. 4496-4505, 2018. 